Goldschmidt 2021 Abstract

https://doi.org/10.7185/gold2021.5021

\section{Mineralogical and isotopic characterization of graphite deposits in the periphery of the Qaidam Basin, northeast Tibetan Plateau, China and its indication to the Great Oxidation Event and Lomagundi-Jatuli Event.}

\section{MAOQIANG YAN ${ }^{1}$, WEI JUNHAO ${ }^{2}$, ZHANG DAOHAN ${ }^{1}$ AND JAN MARTEN HUIZENGA ${ }^{3}$}

${ }^{1}$ School of Earth Resources, China University of Geosciences

${ }^{2}$ School of Earth Resources, China University of Geosciences, Wuhan

${ }^{3}$ Economic Geology Research Centre (EGRU), College of Science and Engineering, James Cook University

Presenting Author: 20121002175@cug.edu.cn

Medium to high-grade Proterozoic metamorphic rocks comprising numerous graphite deposits are widely distributed in the periphery of the Qaidam Basin, Northern Tibetan Plateau, China. We present textural, XRD, and Raman spectroscopy characteristics of graphite, $\delta^{13} \mathrm{C}$ results of graphite and cogenetic calcite, and $\delta^{18} \mathrm{O}$ results of calcite in three graphite occurrences located at the periphery of Qaidam Basin. Graphite displays hexagonal platy, flaky, irregular polygonal, ovate morphologies with occasional spherulitic textures. Relatively high crystallinity is indicated by graphite morphologies, combined with XRD and Raman spectroscopy. Raman microspectroscopy of graphite shows that peak metamorphic temperatures vary between 690 and $801{ }^{\circ} \mathrm{C}$. Graphite $\delta^{13} \mathrm{C}_{\mathrm{V} \text {-PDB }}$ values range between -26.3 and $-21.6 \%$, indicating organic carbon as the major carbon source for graphite. Calcite $\delta^{18} \mathrm{O}_{\mathrm{V} \text {-SMOw }}$ values $(+6.6$ and $+29.5 \%$ ) suggests that the calcite experienced water-rock interaction and modified by metamorphism, possibly causing a decrease of $\delta^{13} \mathrm{C}$ values by $+3 \%$ to $+5 \%$. Calcite $\delta^{13} \mathrm{C}_{\mathrm{V} \text {-PDB }}$ values range between -10.8 and $+3.9 \%$, hence the $\delta^{13} \mathrm{C}_{\mathrm{V}-\mathrm{PDB}}$ values of originally sedimentary carbonates are possibly up to $+6.9 \%$, showing both positive and negative $\delta^{13} \mathrm{C}$ excursion which indicates Lomagundi-Jatuli Event and massive oxidation of organic matter following the Great Oxidation Event. The graphite deposits were probably formed according to the following scenario. About 2.5 Gy ago, a transition from stagnant/sluggish lid to plate tectonics or/and near-global glaciations (Snowball Earth) enhanced volcanic $\mathrm{CO}_{2}$ emissions and increased the atmospheric oxygen content, which led to increased deposition of carbonates and organic carbon by enhanced erosion and weathering of supermountains and a large flux of nutrients delivery to oceans. These rocks formed the protoliths of the Dakendaban and the Jinshuikou Groups' metamorphic rocks. Subsequent orogenic events and regional metamorphism resulted in the recrystallization of organic carbon into graphite and the formation of the graphite deposits. Metamorphic degassing of calc-silicate rocks as a result of prograde metamorphism during collisional orogenesis may have supplied $\mathrm{CO}_{2}$, which participated in the graphite mineralization process. In summary, the biogenetic graphite deposits in orogen around the periphery of Qaidam Basin can be used as strong evidence for the Great Oxidation Event and Lomagundi-Jatuli Event.

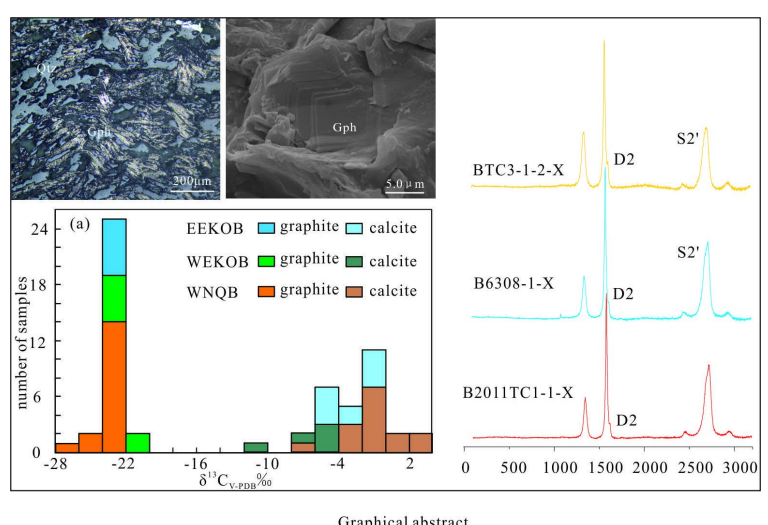

Graphical abstract 